\title{
Socioeconomic and Spatial Impacts of High-Speed Rail on En- terprises: An Ex-Ante Case Study of Ahmedabad Station Area, India
}

\author{
Falendra Kumar Sudan
}

Department of Economics, University of Jammu, Jammu, Jammu and Kashmir - 180 006, India

*Correspondence: fk_sudl@rediffmail.com; Tel.: +91 9419213190

\begin{abstract}
Growth benefits of high speed rail (HSR) for enterprises are not automatic, but require a buoyant local economy and a robust strategy. Against above background, main objectives of ex-ante case study have been to investigate local socio-economic and spatial impacts of proposed HSR project around Ahmedabad station area on Mumbai-Ahmedabad HSR corridor, analyze the opportunities and challenges of HSR development and draw policy implications. Qualitative research methodology has been used to elicit the perceptions and perspectives of randomly selected 43 small, medium and large enterprises. Data has been analyzed using descriptive statistics. The study reveals that HSR induced greater human interaction will activate local economy, improve business efficiency and generate employment. Frequent travels on business trips can influence enterprises decision to settle near HSR station for easy access and likely to promote realty development. The proposed HSR project should be developed in synergy with urban dynamics of cities in transition and metropolitan service cities. Poor public transport connectivity is likely to be a major challenge in improving HSR accessibility and enhancing overall impacts of HSR, which can be improved by developing an integrated urban transport system, for which cooperation of all stakeholders and coherence with firms' strategies is essential.
\end{abstract}

Keywords: high speed rail project; enterprise; infrastructure; socio-economic; spatial impacts; urban development; policy

\section{Introduction}

High speed rail (HSR) refers to a passenger train at a designed speed of $250 \mathrm{~km} / \mathrm{h}$ or more, with a maximum speed of $250 \mathrm{~km} / \mathrm{h}$ for mixed passenger-freight trains [1]. HSR services generate substantial demonstrable effects in urban economic transition [2] and serve as an alternative to traditional rail [3], aircraft [4], and automobiles [5] due to more efficient use of land for transportation [6]. HSR is one of the major determinants of urbanization [2], economic development [7] and economic growth [8, 9]. HSR plays a significant role in development of agglomeration economies [10], regional economy [11], and local economy [12] through wider economic impact [13-15], social impact [16-18], and environmental impact [19-21] on land use pattern [22], land value [23,24], and revenue generation [25] within urban agglomerations and outside the areas of the HSR network by connecting the neighborhood locations [16], which also depends on buoyancy of the local urban conditions $[2,26]$.

HSR improves transportation system [27], increases accessibility [28,29], enhances regional attractiveness and development [30], improves businesses [31,32], fosters new opportunities, modernity and innovation [33], which increase employment growth and boost urban productivity [2] due to time savings [34,35], better market information [26], significant reduction in business cost [34], and agglomeration benefits [7]. Despite high investment in HSR development [36], HSR benefits the regional governments from increase in tax revenue [23,37], tourist inflow [38-41], and better performance of private investors [42,43]. Impact of HSR projects on regional tax revenue [23], productivity [44], and urban expansion [45] has been widely analyzed. Chen and Haynes [8] analyzed 
HSR impact on economic agglomeration and growth, which benefits small and medium-sized cities around megacities [46]. Large cities attract additional resources from nearby small and medium-sized cities, thereby reduce agglomeration capacity of these cities, while larger cities benefits more compared to small and medium-sized cities due to resource outflow. Therefore, efficient market and proactive government policies are essential to guarantee economic development and competitiveness [47].

Zhao and $\mathrm{Yu}$ [48] studied micro-level accessibility impacts of HSR project. At the micro-level, HSR services offer wider economic effects [49] through improved mobility patterns [50], energy consumption [51], and service quality [52]. This facilitates communication and cooperation among businesses [53], and offers time-space shrinking, spurs business and boosts leisure travel [31,32]. Boulton, Dedekorkut-Howes, and Byrne [54] argued that HSR impact remains low in sub-urban areas compared to city centre. However, the socio-economic and spatial impacts of HSR project [55] around station area have received little attention. Therefore, the present study is an attempt in this direction.

Despite high cost of HSR projects [9,32,56] compared with tax revenues [37], many economies invest in HSR development [57]. For instance, the ratio of infrastructure investment to tax revenues is as high as $49.1 \%$ in South Asia [58]. Growth benefits of HSR services are not automatic $[1,9,26]$, but require a buoyant local economy and a robust strategy to reap the opportunities of improved transport links. Huge potential of HSR to promote economic development can be tapped by building high class urban places consisting of new parks and open spaces including residential and commercial centers and tourism development [39,40,59,60]. Against the above background, the main objectives of this ex-ante case study have been to investigate the local socio-economic and spatial impacts of proposed HSR project around Ahmedabad station area on Mumbai-Ahmedabad HSR corridor, analyze the opportunities and challenges of HSR development and draw policy implications.

\section{Materials and Methods}

There are a number of methodological issues related to this research linking to intrinsic complexities to separate the HSR impacts from other development factors [61] including short-term and long-term effects [1,62]. There exists no reflexive and methodical link between HSR and spatial and socio-economic impact [9]. Therefore, study of impacts of major transportation projects should focus on regional and time specific impacts $[9,32,63]$. Extant research on local socio-economic and spatial impacts of HSR is quite scant, which is investigated in this ex-ante case study with a major goal to integrate HSR development into policy and planning.

Qualitative research methodology has been used to elicit the perceptions and perspectives [64] of the targeted population on the phenomenon under investigation [65]. The study has used descriptive ex-ante case study of proposed Ahmedabad-Mumbai HSR project [66]. Ex-ante case study reflects a 'what if analysis' [67] (p. 124). This has been used to understand socioeconomic and spatial impacts of HSR in the Ahmedabad station area and to draw the best policy options for efficient implementation of the project. Descriptive case study approach has been highly useful to understand an unexplored phenomenon [68]. A comprehensive and in-depth analysis of the targeted population [69] have been undertaken to draw the practical lessons. The data and information have been collected from the sampled small, medium, and large enterprises operational in Ahmedabad station area using random sampling technique. This ex-ante case study has analyzed issues such as enterprises preferences to relocate their workplaces to near the HSR station area due to suitable accessibility, which can improve the business operations [31,32], socio-economic and spatial impacts [55] including employment opportunities, long-distance workplaces, surge in property demand, land 
values, and property prices around station [70] and other types of impacts [10]. All efforts have been made to maximize transparency and minimize the bias in this qualitative research.

This ex-ante case study is qualitative and provides the social impacts of HSR on daily life and citizens' lives; economic impacts of HSR on urban economic opportunities, property development, urban quality, urban dynamics, local tourism and recreational activities, indirect effects around station area, transport demand of enterprises and enterprise operations; and spatial impacts of HSR on redistribution and relocation, and impact on creating an extended functional region. The study has also analyzed the opportunities and challenges of HSR development and drawn significant policy implications.

Micro-survey approach has been used to analyze the objectives of the case study using primary data collected from management executives of local small, medium and large enterprises around proposed HSR station area in Ahmedabad city of Mumbai-Ahmedabad corridor to ascertain the likely magnitudes of socio-economic and spatial effects. Interviews of the management functionaries involved in enterprise operations have been conducted to ascertain the impacts of the proposed HSR Mumbai-Ahmedabad corridor focusing on how enterprises and employees are expected to use HSR and how the use of HSR is likely to impact their work patterns, daily life and enterprise decision-making. Keeping in view the local economic structure of the Ahmedabad city, the interviewees have been selected as diversely as possible. A total of 43 enterprises consisting of small enterprises (24), medium enterprises (11) and large enterprise (8) from secondary and tertiary industries have been selected as sample size. The selected enterprises were engaged in manufacturing (15), real estate (4), wholesale and retail (3), banking and finance (3), information technology (2), commercial services (2), environmental and sanitation (3), scientific research and technical services (1), transport (2), hotels (3), education (3), and culture and public management (2). The data has been analyzed using descriptive statistics.

\section{High Speed Rail: Experiences around the World}

The first HSR line, called the Shinkansen, was built in Japan, which linked Tokyo to Osaka in 1964 with a speed of $210 \mathrm{~km} / \mathrm{h}$ in 3 hours and 10 minutes, and $270 \mathrm{~km} / \mathrm{h}$ in 2 hours and 30 minutes in 1992 using existing railway stations, while some cities and towns were served by new stations. In Europe, the first HSR lines were built in the 1980s by connecting important cities involving private operators and the European Union funding beginning with France connecting Paris and Lyon in 1981 for regional development followed by Spain connecting Madrid and Seville in 1992, which becomes the largest HSR network in Europe by 2010 and reaching over $3200 \mathrm{~km}$ in 2020. In 1991, Germany started InterCity Express to connect major cities of France, the Netherlands, Switzerland, Denmark, Belgium, and Austria. In 1992, Italy started its first HSR service connecting Rome and Florence.

In the Republic of Korea, the operation of HSR service since 2004 significantly reduced intercity travel. In the People's Republic of China, a new generation of HSR with a maximum speed of $350 \mathrm{~km} / \mathrm{h}$ was opened in 2008 as green-field project connecting most of the metropolitan regions by 2013 and likely to reach 30,000 km by 2020 to rejuvenate economic activities in most of the cities in western and central regions. Taipei, China operates the privately funded HSR for commercial, residential, and recreational needs.

In recent years, the Asian countries of India, Indonesia, and Thailand have proposed to develop HSR lines. In 2010, India announced construction of seven HSR lines connecting major cities, with its first 508-km HSR line connecting Mumbai and 
Ahmedabad, for which India and Japan entered an agreement in 2015 to adopt Japanese Shinkansen technology to be operational by late 2023 at a cost of US\$16 billion with funding from the Japan International Cooperation Agency (JICA). In 2008, Indonesia announced the Java HSR project connecting Jakarta and Surabaya with 730-km HSR line and its $150-\mathrm{km}$ initial phase at an estimated cost of US\$5.5 billion as part of the People's Republic of China's One Belt One Road initiative is likely to be operational by early 2021. In 2010, Thailand approved five HSR lines covering 1,500-km network converging Bangkok at estimated cost of $\$ 30$ billion under official development aid projects to be completed by 2036, with operation of first phase in 2021.

Japan initiated rail-integrated land development using the Shinkansen corridors for development of services and industries agglomerations, which has had tremendous impact on Japanese economy and society. The Republic of Korea integrated regional public transport with HSR corridors and stations to increase accessibility and revenue. Taipei, China established station-to-city center bus services to increase ridership and revenue growth. In China, HSR services have led to improved accessibility and expansion of business-centric regions [29], which led to increase in employment, average income, production, and property prices [70]. HSR resulted in savings of travel time [34], better safety, comfort, punctuality, and frequency of trains, which enhanced business activity and productivity [29]. Improved accessibility strengthens intercity economic links and builds urban agglomerations along the HSR corridors. HSR is preferred over automobiles and planes for long distance travel due to better safety, frequency and ride quality. HSR generates a very low carbon footprint [19] compared with other high-capacity transport. In construction phase, HSR led to high land prices and property tax revenues near the HSR stations and transformed the regional economy. Despite rapid growth in HSR networks, the potentials and challenges of HSR infrastructure remained and need to be addressed.

\section{Mumbai-Ahmedabad High Speed Rail}

The Vision 2020 of the Indian Railways identified the Mumbai-Ahmedabad HSR (MAHSR) corridor with route length of $506 \mathrm{kms}$, as one of the HSR corridors to be developed in India, for which a memorandum of cooperation between the Government of Japan and the Government of India was signed in December 2015. In early 2016, the JICA assigned Japan International Consultants for Transportation, Co., Ltd. for consulting services in formulating the technical standards for the MAHSR corridor. In mid-2017, officials of the National High Speed Rail Corporation Limited visited Japan to gain knowledge of Japan's HSR system under JICA's capacity building and training program. The work on MAHSR corridor with Japanese bullet train system-the Shinkansen was commenced in 2018 with an estimated cost of US\$14.52 billion to be completed by 2023. MAHSR will cover a distance of 508 kilometers $(\mathrm{km})$ between Mumbai and Ahmedabad in around 2 hours at maximum speed of $320 \mathrm{~km} /$ hour covering 12 HSR stations with Mumbai, Ahmedabad, and Sabarmati as busy stations and Surat and Vadodara as semi-busy stations. 


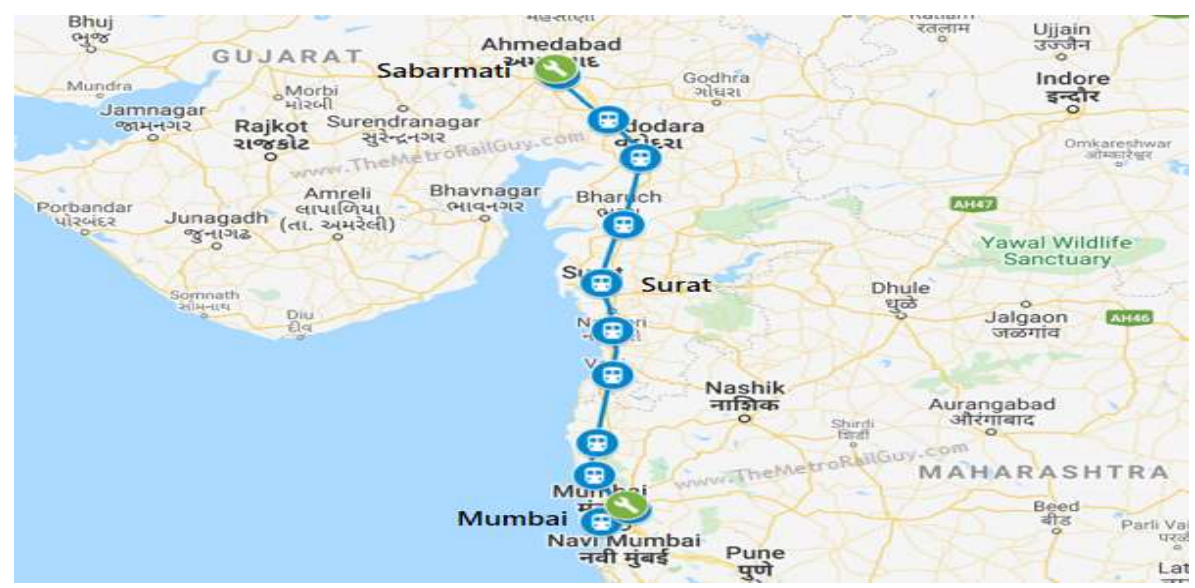

Figure1. Mumbai-Ahmedabad bullet train route

Average distance between proposed stations has been $46 \mathrm{kms}$ and the proposed HSR fare is 1.5 times of $1 \mathrm{~A}$ class fare of Indian railways. Vadodara, Ahmedabad, and Sabarmati HSR stations are located on top of a conventional line station. New metro rail lines are under construction close to Ahmedabad HSR Station and Sabarmati HSR Station. A new central business district and a metro rail station are planned to be developed to connect Mumbai-Bandra Kurla Complex. MAHSR project explored integrated station area development for reducing $\mathrm{CO} 2$ emissions and improving the quality of life in its surroundings. Mumbai-Ahmedabad HSR is expected to carry 40,000 passengers daily in 2023 , which is likely to be 200,000 by 2053 . Initially, the alignment was a mix of viaduct and grade, which has been changed to complete alignment on viaduct and a perfect grade separation throughout the alignment. MAHSR project is expected to be completed over a period of seven years from 2017 to 2023 [71].

\section{Results}

\subsection{Gender, Age and Expected HSR Trips}

Table 1 provided the information on the sample characteristics by gender, age and expected HSR trips by enterprises. Majority of the respondents were males and above 25 years of age engaged as high level management executives in the selected enterprises and performed travel linked professional tasks. Besides leisure trips, majority of respondents were expected to perform business trips covering distance of more than $200 \mathrm{~km}$ with likely trip duration of less than two days after the operation of HSR.

Table 1. Gender, age and expected HSR trips by enterprises (\%).

\begin{tabular}{cccc}
\hline Characteristics & Small & Medium & Large \\
\hline Gender & & & \\
Male & 79.2 & 72.7 & 75 \\
Female & 16.7 & 27.3 & 25 \\
Age & & & \\
$<25$ years & 41.7 & 27.3 & 25 \\
$>25$ years & 58.3 & 63.3 & 75 \\
Trip purposes & & & \\
Business trips & 66.7 & 81.8 & 87.5 \\
Leisure trips & 33.3 & 18.2 & 12.5 \\
Trip Distance $(\mathrm{km})$ & & & \\
$<200$ & 58.3 & 27.3 & 12.5 \\
$>200$ & 41.7 & 72.7 & 87.5 \\
\hline
\end{tabular}




\begin{tabular}{cccc}
\hline Average Trip Duration (days) & & & \\
$<2$ days & 83.3 & 81.8 & 75 \\
$>2$ days & 16.7 & 18.2 & 25 \\
\hline
\end{tabular}

\subsection{Social Impacts of HSR}

Table 2 and table 3 provided the social impacts of HSR on citizens' daily life. Enterprises expected that HSR is likely to impact the people's daily life due to improve service reliability during extreme weather conditions, provide comfortable and spacious carriages and reduce travel time significantly [31,32]. It was expected that HSR induced greater human interaction can activate the local economy, and increase consumption and capital investment, thereby can improve their business efficiency and generate employment [2].

Table 2. Social impacts of HSR on daily life (\%).

\begin{tabular}{cccc}
\hline Social Impacts & Small & Medium & Large \\
\hline Impacts on daily life & 91.7 & 90.9 & 87.5 \\
Enhance service reliability & 70.8 & 81.8 & 50 \\
More comforts and spacious carriages & 66.7 & 36.4 & 37.5 \\
Shorter travel time & 83.3 & 63.3 & 62.5 \\
Impacts on regional economy & 70.8 & 54.5 & 75 \\
Activate local economy & 75 & 36.4 & 37.5 \\
More consumption activities & 66.7 & 27.3 & 37.5 \\
More capital investment & 54.2 & 45.4 & 50 \\
Improve business efficiency & 75 & 27.3 & 37.5 \\
Increase in workers & 33.3 & 36.4 & 12.5 \\
\hline
\end{tabular}

Table 3 showed how the opening of Mumbai-Ahmedabad HSR is expected to impact the citizens' lives. Most small enterprises expressed that introduction of HSR is likely to intensify inter-urban integration and reunion of long-distance couple, whereas large number of medium and large enterprises expected that HSR is likely to influence more frequent inter-city get-togethers linked with business or private purposes, which can strengthen the social networks and create new business opportunities [33]. Some enterprises expressed that frequent travels on business trips can influence their decision to settle near HSR station for easy access from home and increase their trips for shopping and concerts. Therefore, opening of the HSR station is likely to promote realty development around HSR station [45].

Table 3. Impact on citizens' lives (\%).

\begin{tabular}{cccc}
\hline Impact on Citizens' Lives & Small & Medium & Large \\
\hline Intensify inter-urban integration & 83.3 & 63.3 & 62.5 \\
Reunion of long-distance couple & 62.5 & 45.4 & 37.5 \\
Frequent inter-city get-togethers & 33.3 & 72.7 & 50 \\
Build social networks & 33.3 & 36.4 & 50 \\
Facilitate business opportunities & 54.2 & 36.4 & 75 \\
\hline
\end{tabular}

\subsection{Economic Impacts of HSR}

Table 4 revealed the enterprises expectation of the impact of HSR investment and change in accessibility on economy via lower travel costs, less travel time and improvement in services through greater human interaction, information exchange, goods movement, which can improve employment and productivity. 
Table 4. Economic impact of change in accessibility (\%).

\begin{tabular}{cccc}
\hline Impact on Investment and Accessibility & Small & Medium & Large \\
\hline Lower travel costs & 83.3 & 81.8 & 87.5 \\
Less travel time & 87.5 & 72.7 & 62.5 \\
Improve services & 70.8 & 45.4 & 75 \\
Greater human interaction & 66.7 & 45.4 & 62.5 \\
Better information exchange & 54.2 & 36.4 & 37.5 \\
Speedier movement of goods & 33.3 & 27.3 & 37.5 \\
Increase employment & 20.8 & 27.3 & 25 \\
Enhance productivity & 20.8 & 45.4 & 25 \\
\hline
\end{tabular}

Table 5 revealed the expected impact of HSR on urban economic opportunities. The proposed HSR corridor is likely to increase opportunity for urban economic expansion in the cities connected to the line via external impulse to an urban region [39,40,59,60]. Enterprises expressed that HSR is expected to reduce transport costs, increase welfare potential within the corridor economy and facilitate transition from industrial to service economy. HSR induced external accessibility can increase the urban economic potential in corridor region. However, side effects of improved external accessibility such as the loss of activities towards larger cities, can expand their catchment areas and need careful attention, because larger cities along the HSR corridor already possess high economic potential to attract new enterprises due to availability of well-educated residents, consolidated business clusters and robust legal and fiscal regimes. Therefore, enterprises in larger cities are likely to gain further through improved external accessibility.

Table 5. Impact on urban economic opportunities (\%).

\begin{tabular}{cccc}
\hline Impact on Urban Economic Opportunities & Small & Medium & Large \\
\hline Reduces transport costs & 29.2 & 18.2 & 37.5 \\
Increase welfare potential & 20.8 & 27.3 & 25 \\
Facilitate transition to service economy & 33.3 & 27.3 & 37.5 \\
High economic potential & 66.7 & 54.5 & 50 \\
Attractive location for new companies & 20.8 & 18.2 & 25 \\
Well-educated residents & 33.3 & 27.3 & 37.5 \\
Consolidated business clusters & 45.8 & 36.4 & 25 \\
Attractive legal and fiscal regimes & 16.7 & 27.3 & 37.5 \\
\hline
\end{tabular}

Table 6 revealed that the proposed HSR is expected to significantly affect the property values of land around the station area. A station area refers to both permanently and temporarily inhabited area of the city, which provides connection to both material and immaterial flows. Enterprises expressed an increase in transactions of land and building sites [22-24], and also a surge in land and apartment prices and rentals [70] in the station area after the operation of HSR. Residential property prices are likely to be affected marginally in the station area. High property values around station areas can stimulate land speculation and land hoarding by property developers. High land values can negatively influence overall development of station area in long run due to land speculation.

Table 6. Effect on property development in the station area (\%).

\begin{tabular}{cccc}
\hline Property Development & Small & Medium & Large \\
\hline Surge in property values of land & 79.2 & 45.4 & 62.5 \\
Increase transactions of land and building sites & 58.3 & 81.8 & 37.5 \\
Increase in land prices & 62.5 & 54.5 & 25 \\
Increase in apartment prices & 45.8 & 27.3 & 25 \\
\hline
\end{tabular}




\begin{tabular}{cccc} 
Surge in residential property prices & 33.3 & 54.5 & 12.5 \\
Increase in rentals & 50 & 18.2 & 37.5 \\
Surge in land speculation & 20.8 & 27.3 & 37.5 \\
Land hording by property developers & 37.5 & 36.4 & 25 \\
\hline
\end{tabular}

Table 7 revealed that the operation of HSR is expected to create new urban images and boost economic development of station areas. Besides potential business centers, HSR is likely to provide potential public spaces and urban quality around station areas. Urban quality of HSR station areas is likely to be influenced by better urban design and development of cultural, recreational, educational and environmental facilities. Enterprises expressed that urban quality in station areas can be improved by better urban structure, modern architecture, functional diversity, and quality of public space.

Table 7. Urban quality of station areas (\%).

\begin{tabular}{llll}
\hline Urban Quality in Station Areas & Small & Medium & Large \\
\hline Improved urban structure & 79.2 & 72.7 & 75 \\
Modern and international architecture & 66.7 & 54.5 & 50 \\
Higher functional diversity & 58.3 & 81.8 & 25 \\
Better quality of public space & 83.3 & 27.3 & 25 \\
\hline
\end{tabular}

Table 8 revealed the expectation of enterprises regarding the synergy between HSR and urban dynamics in HSR corridor. Enterprises expressed that the proposed HSR should be developed in synergy with urban dynamics of cities in transition as well as metropolitan service cities. Urban development is highly dependent on transport infrastructure development for better accessibility to city centre, suburbs and the region. It also influenced the performance of existing and new transportation systems. Robust synergy between HSR and urban dynamics is likely to transform the urban economy via development of service and high-tech enterprises including new small enterprises around the station area.

Table 8. Synergy between HSR and urban dynamics (\%).

\begin{tabular}{cccc}
\hline HSR and Urban Dynamics & Small & Medium & Large \\
\hline Urban transformation & & & \\
Growth in service and high-tech enterprises & 79.2 & 81.8 & 62.5 \\
Reduce unemployment & 54.2 & 45.4 & 37.5 \\
Integrate young people in urban society & 20.8 & 18.2 & 25 \\
Rediscover urban value of neighborhoods & 29.2 & 36.4 & 37.5 \\
Improve urban dynamics & 41.7 & 45.4 & 62.5 \\
Attract service and leisure economy & & & \\
Offices & 25 & 27.3 & 37.5 \\
Services & 29.2 & 54.5 & 50 \\
Shops & 20.8 & 27.3 & 25 \\
Cultural establishments & 41.7 & 36.4 & 37.5 \\
Public facilities & 16.7 & 18.2 & 25 \\
Housing & 37.5 & 27.3 & 12.5 \\
High-quality open space & 12.5 & 36.4 & 12.5 \\
Offices & & & \\
Creation of new facilities around station & 58.3 & 36.4 & 50 \\
Entertainment and cultural venues & 29.2 & 27.3 & 37.5 \\
Congress and exhibition facilities & 16.7 & 27.3 & 50 \\
International head offices & 12.5 & 18.2 & 62.5 \\
\hline
\end{tabular}




\begin{tabular}{cccc} 
Growth in new small-scale enterprises & 62.5 & 54.5 & 37.5 \\
Growth in tourist industry & 29.2 & 36.4 & 50 \\
Increase in employment & 33.3 & 18.2 & 25 \\
\hline
\end{tabular}

Table 9 is devoted to expected impact of HSR on local tourism and recreational activities. This table revealed that opening of HSR is likely to benefit the enterprises to arrange tourist itineraries easily due to abundant supply of tickets, significantly reduce travel time [34], and provide clean and comfortable ride for shorter trips. However, high fares can restrict number of travelers, but preferred by executives and the younger generation compared to the older generation employees. Better accessibility to event cities is expected to increase the catchment area of small enterprises more compared to medium and large enterprises. This is likely to reduce the pressure of organizing fans to concerts due to their self participation in such events.

A HSR station area includes the zone of influence and development perimeter, which covers three development zones on the basis of accessibility and influence. Primary zone lies within five to ten minutes reach, secondary zone can be reached within 15 minutes using complementary transport, and tertiary development zone is more than 15 minutes travel time from HSR station. Table 10 provided the expectation of enterprises regarding indirect effects of HSR around station area. Enterprises expected significantly high effects of the proposed HSR in primary zone of the station area due to high saving in travel time and lesser use of complementary transport. High proximity to HSR network is expected to enhance its status as a location, which can attract more high-grade office and residential functions, increase land and real estate values and induce high and dense construction around the station area. Secondary zones can also attract some high-grade functional areas, however, the gains in property value and building density is expected to be lower compared to the primary zones of the proposed HSR station area, which may limit investment in these zones in initial phase of HSR operation. Tertiary development zones are also likely to gain from improved accessibility, but unlikely to experience direct development effects due to the introduction of the HSR line.

Table 9. Impact on local tourism and recreational activities (\%).

\begin{tabular}{cccc}
\hline Impact on Local Tourism and Recreations & Small & Medium & Large \\
\hline Easier to arrange tourist itineraries & 50 & 36.4 & 50 \\
Shorten travel time & 70.8 & 81.8 & 75 \\
Clean and comfortable ride & 87.5 & 63.3 & 87.5 \\
Prefer by younger generation & 62.5 & 27.3 & 25 \\
Better accessibility to event cities & 62.5 & 36.4 & 25 \\
Enlarge catchment area of enterprises & 70.8 & 45.4 & 37.5 \\
Reduce pressure of organizing concerts & 33.3 & 18.2 & 12.5 \\
Increase hotel occupancy & 12.5 & 18.2 & 12.5 \\
Construction of new hotels & 16.7 & 18.2 & 12.5 \\
\hline
\end{tabular}

Table 10. Indirect effects of HSR around station area (\%).

\begin{tabular}{cccc}
\hline Effect around Station Area & Small & Medium & Large \\
\hline Primary zone & & & \\
Maximum saving of travel time & 58.3 & 81.8 & 75 \\
Less use of complementary transport & 25 & 36.4 & 12.5 \\
Benefits of improved location status & 20.8 & 27.3 & 12.5 \\
Establishment of high-grade offices and residences & 45.8 & 27.3 & 37.5 \\
Surge in land and real estate values & 37.5 & 63.3 & 50 \\
Attractive construction & 70.8 & 36.4 & 62.5 \\
Secondary zones & & & \\
\hline
\end{tabular}




\begin{tabular}{cccc}
\hline Establishment of high-grade functional areas & 29.2 & 81.8 & 87.5 \\
Lower gain in property value & 29.2 & 54.5 & 62.5 \\
$\quad$ Less investment & 29.2 & 54.5 & 37.5 \\
Tertiary development zones & & & \\
Improved accessibility & 79.2 & 72.7 & 62.5 \\
Less direct development & 20.8 & 27.3 & 37.5 \\
\hline
\end{tabular}

Manufacturing enterprises transport products through railways and highways. However, sales and procurement personnel are likely to switch to HSR for business trips. Table 11 revealed that service enterprises are likely to choose HSR due to significant reduction in travel time for meeting clients. Enterprises in culture and entertainment activities are likely to rely heavily on HSR to promote business development. Thus, many small and medium enterprises can switch from bus and car to HSR for inter-city travel.

Table 11. Impact on transport demand of enterprises (\%).

\begin{tabular}{cccc}
\hline Transport Demand of Enterprises & Small & Medium & Large \\
\hline Facilitate business trips & 83.3 & 63.3 & 62.5 \\
Shorten travel time for meeting clients & 83.3 & 72.7 & 75 \\
Promote enterprise development & 54.2 & 36.4 & 37.5 \\
\hline
\end{tabular}

Table 12. Impact on enterprise operations (\%).

\begin{tabular}{cccc}
\hline Impacts on Business Operations & Small & Medium & Large \\
\hline Site selection of enterprises & & & \\
$\quad$ Local policy & 62.5 & 90.9 & 100 \\
Land price & 70.8 & 72.7 & 100 \\
Transport accessibility & 66.7 & 90.9 & 87.5 \\
Logistics services & 87.5 & 63.3 & 62.5 \\
Decision-making of enterprise operations & & & \\
Influence basic enterprise operations & 58.3 & 72.7 & 25 \\
Influence enterprise travel & 62.5 & 72.7 & 87.5 \\
Facilitate human resource allocation & 45.8 & 36.4 & 37.5 \\
Broaden enterprise catchment areas & 58.3 & 45.4 & 62.5 \\
Faster enterprise responses & 33.3 & 63.3 & 37.5 \\
Establish a branch office & 20.8 & 54.5 & 25 \\
Facilitate employment of expert & 12.5 & 45.4 & 25 \\
Expand training business & 12.5 & 27.3 & 12.5 \\
Improve investment of non-local enterprises & 25 & 27.3 & 12.5 \\
Bring new enterprise opportunities & 41.7 & 54.5 & 62.5 \\
Promote local enterprise & 37.5 & 54.5 & 37.5 \\
\hline
\end{tabular}

Table 12 provided the impact of proposed HSR on enterprise operations. Site selection of the enterprises is likely to be influenced by local policy, land price, transport accessibility, and logistics services, which varied by the type of enterprise. Site selection of large and medium enterprises is likely to be strongly influenced by local government's preferential policies, availability of sufficient land and transport accessibility. Operation of HSR is likely to influence relocation choices of enterprises in new economic zones. Small enterprises engaged in commercial trade services are likely to establish branch offices in mega-city Mumbai with HSR convenience of intra-city travel. HSR access is likely to strongly influence the site selection of enterprises. Therefore, there is need for more concerted land development around HSR station to reap the opportunities to attract new enterprises. Most large enterprises expected that the opening of HSR is unlikely to strongly influence their basic enterprise operations, but likely to 
significantly influence the enterprise travel due to lower travel expenses, time savings, and high productivity. Most small and medium enterprises expected that the HSR is likely to facilitate allocation of human resources and expand their catchment areas. Shorter travel time between cities is likely to help staff of small enterprises to cover neighboring cities more easily and their businesses can be expanded to achieve regional scale economy and faster enterprise responses. Most of medium enterprises are likely to open a branch office in Mumbai with greater inter-city integration. Operation of HSR is also likely to increase employment of expert trainers, expand training activities, increase participation in trade exhibitions, improve investment of non-local enterprises, and expand new opportunities to promote local enterprises. Therefore, introduction of HSR is expected to positively influence operations of most enterprises, which is likely to be stronger for service enterprises.

\subsection{Spatial Impacts of HSR}

Table 13 provided the expectation of the enterprises on the impact of HSR on spatial development. It is expected that introduction of HSR is likely to change the absolute and relative accessibility of different cities, which can increase mobility opportunities [50,72], enable business people and tourists to travel longer distances. HSR induced relative accessibility can influence choice of location for housing and place of work for individuals and office sites for businesses and result in regional spatial redistribution.

Table 13. Impact of HSR on spatial development (\%).

\begin{tabular}{cccc}
\hline Spatial Development Effects & Small & Medium & Large \\
\hline Increase mobility opportunities & 62.5 & 81.8 & 87.5 \\
Enable longer business travel & 29.2 & 90.9 & 62.5 \\
Facilitate tourists to travel longer distances & 66.7 & 54.5 & 37.5 \\
Choice of location & 20.8 & 27.3 & 12.5 \\
Housing & 16.7 & 45.4 & 50 \\
Place of work & 12.5 & 45.4 & 37.5 \\
Office sites & 12.5 & 27.3 & 25 \\
\hline
\end{tabular}

Table 14. Impact of HSR on redistribution and relocation (\%).

\begin{tabular}{cccc}
\hline Redistribution and Relocation Impact & Small & Medium & Large \\
\hline Population growth & 87.5 & 72.7 & 62.5 \\
Employment levels & 79.2 & 54.4 & 37.5 \\
Real estate market values & 41.7 & 63.3 & 75 \\
Gross Value Added & 45.8 & 36.4 & 50 \\
Gross Disposable Household Income & 62.5 & 54.5 & 25 \\
Dominant cities to become more competitive & 37.5 & 27.3 & 12.5 \\
Improve location advantages & 54.2 & 36.4 & 25 \\
Attract business activity to intermediate cities & 20.8 & 36.4 & 37.5 \\
Meetings of metropolitan professionals & 16.7 & 18.2 & 25 \\
Mid-level business & 12.5 & 27.3 & 25 \\
Technical consultancy firms & 8.3 & 18.2 & 37.5 \\
Urban tourism & 16.7 & 27.3 & 12,5 \\
\hline
\end{tabular}

Table 14 provided the expectation of the enterprises on redistribution and relocation effects of opening of HSR corridor. It is expected that the cities along HSR corridor are likely to experience stronger redistribution of social, economic and spatial elements in terms of population, employment, real estate prices, gross value addition, and gross disposable household income. Dominant cities along HSR corridor are expected to become more competitive after opening of the line and improve their location advantages. HSR is likely to 
create new opportunities to conduct business in larger central cities, attract some business activities such as professionals' meetings, mid-level business, consultancy and tourism to the intermediate cities.

Table 15 revealed the expected impact of HSR on creating an extended functional region. The proposed HSR corridor is likely to connect Mumbai and Ahmedabad metropolitan areas by linking a chain of small cities, which may create an integrated corridor economy. In short-term, HSR is expected to integrate goods and services market, along with labor, commercial, interpersonal and leisure activities, while it is expected to relocate the households and firms along its corridor in medium-term. The proposed HSR corridor is likely to create a completely new location pattern with high travel volumes along with new travel patterns after the opening of new line, which can improve the effectiveness of regional labor markets via reduce information decay and easier labor migration.

Table 15. Impact of HSR on creating an extended functional region (\%).

\begin{tabular}{cccc}
\hline Short-Term and Medium-Term Gains & Small & Medium & Large \\
\hline $\begin{array}{c}\text { Short-term gains } \\
\text { Integrate the goods and services market }\end{array}$ & 91.7 & 72.7 & 87.5 \\
Integrate labor, commercial, and leisure activities & 70.8 & 54.5 & 62.5 \\
Medium-term gains & & & \\
Relocate households and firms along its corridor & 54.2 & 36.1 & 25 \\
$\quad$ Larger travel volumes & 70.8 & 45.4 & 50 \\
Change in travel patterns & 33.3 & 27.3 & 62.5 \\
Facilitate effectiveness of regional labour markets & 20.8 & 27.3 & 37.5 \\
\hline
\end{tabular}

\subsection{Opportunities and Challenges of HSR development}

Table 16 revealed that the proposed HSR corridor is expected to provide robust opportunity for urban industry to upgrade and transform cities along the line. HSR development is likely to attract headquarters and R\&D centres of multinational corporations in megacities along the proposed corridor. The availability of talented manpower and public institutions in cities connected with the proposed corridor may facilitate further development of existing high technology and knowledge-intensive manufacturing and can provide other connected cities to establish such industries and expand their markets. In brief, concerted efforts should be made to tap human capital resources and prepare the robust urban policy and planning to maximize the outcomes of the proposed HSR development.

Table 16. Opportunities and Challenges of HSR development (\%).

\begin{tabular}{|c|c|c|c|}
\hline Opportunities and Challenges & Small & Medium & Large \\
\hline \multicolumn{4}{|l|}{ Opportunities } \\
\hline Upgradation and transformation of urban industry & 58.3 & 72.7 & 75 \\
\hline Establishment of headquarters and R\&D centres of MNCs & 37.5 & 81.8 & 62.7 \\
\hline $\begin{array}{c}\text { Transformation to technology and knowledge- intensive } \\
\text { manufacturing }\end{array}$ & 66.7 & 54.5 & 37.5 \\
\hline Expansion of existing technology and knowledge-intensive activities & 41.7 & 36.4 & 87.5 \\
\hline Attraction and expansion of markets & 70.8 & 27.3 & 25 \\
\hline \multicolumn{4}{|l|}{ Challenges } \\
\hline Very expensive transport mode & 58.3 & 18.2 & 37.5 \\
\hline Relatively high prices of HSR & 54.2 & 27.3 & 25 \\
\hline Poor public transport connectivity to station & 41.7 & 45.4 & 50 \\
\hline Uncertainty in synergy between HSR and urban transformation & 62.5 & 72.7 & 62.5 \\
\hline Competition between different layers of governments & 41.7 & 45.4 & 37.5 \\
\hline Assuring qualitative growth of high-end service and leisure functions & 33.3 & 27.3 & 37.5 \\
\hline
\end{tabular}


Table 16 also provided the expressed potential implications and planning challenges of direct and indirect impacts of HSR development. Enterprises opined that HSR is likely to be a very expensive transport mode for passengers and may be out of reach of the income of most people. Other direct challenge include poor accessibility to the stations due to inadequate public transport between station areas and city centers, which require construction of highways to connect the HSR stations and the city centre so that passengers can save their travel time using public transport. Therefore, poor public transport connectivity is likely to be a major challenge in improving HSR accessibility and enhancing overall attractiveness of HSR, which can be improved by developing an integrated urban transport system.

HSR development is likely to face potential implications and planning challenges of indirect effects. It is expected that cities connected to HSR will likely to perform better than the unconnected cities, which can be addressed by redistribution of tourism, business and the knowledge economy along the HSR line, otherwise, cities with high-quality resources will become more attractive places to visit and conduct business. Cities with robust knowledge-intensive sectors such as Anand and Vadodra and well-developed tourism, such as Sabarmati and Shirdi will gain more from introduction of HSR, whereas smaller cities without such potential will likely to face severe challenges in development process. Therefore, planners and policy-makers must consider these challenges to avoid the over-estimation or underestimation of development opportunities in the proposed HSR corridor. Enterprises opined that HSR development has immense potential to reconstruct the urban spatial system and achieve qualitative urbanization and can transform a manufacturing-centered economy to a services-centered urban economy.

Addressing the synergy between HSR development and the strategy of urban transformation is essential. There is high level of competition between different layers of governments for urban development. Local urban administration is responsible for governance of local development and prosperity. The proposed HSR is considered as an opportunity by the enterprises to address the challenges to stimulate urban economy and attract high-end services and leisure functions in the HSR station area. Besides, assuring qualitative growth of high-end services and leisure functions is also considered as a major challenge to maximize the likely benefits of proposed HSR development. Therefore, the planning challenges of HSR development should be addressed through integrated transport development to realize the potential impacts of HSR.

\section{Conclusions and Policy Implications}

HSR project is likely to create significant socio-economic and spatial impacts and increase development potential of station area and connected larger cities than intermediate and small cities along the corridor. The proposed HSR station area development has immense potential to generate significant enterprise growth between Mumbai-Ahmedabad corridor and the linked cities served. It can considerably affect business traffic and work patterns of enterprises due to improved accessibility and likely surge in business travel demand between the two mega cities and cities connected to the corridor. However, business operations are more likely to be concentrated in major cities from the local surrounding areas. Land and property values are expected to significantly surge after the operation of HSR, which are unlikely to benefit business activities. Tourism industry is likely to gain significantly after HSR operation specifically in already established religious tourist destinations, which will lead to considerable surge in hotels and other tourist services. Urban transformation and development is likely to be experienced around HSR station areas. Primary and secondary zones around station areas are expected to experience different impacts of HSR development project. Improved transportation may ease access to certain occupations, increase employment opportunities, improve productivity and influence relocation of enterprises significantly. 
HSR could play a more significant role for enterprises to implement a strategy of business expansion through improved access to skilled manpower resources and better transport accessibility. Therefore, HSR has strong potential to expand labor market and improve mobilization of talented manpower. It is expected that expansion of market can enable enterprises to improve their scale and productivity due to reduced salary and increased access to talented human capital resources. HSR can positively impacts major cities compared to more peripheral areas of the corridor economy. Therefore, to achieve inclusive and sustainable growth, it is essential to promote quality transport infrastructure investment for equitable growth of the corridor economy. HSR can attract advanced services enterprises compared to manufacturing companies in station areas and may benefit business tourism, and cultural events and conferences. However, expected reduction in hotel stays can reduce tourist expenditure and consumption of hotel services significantly. HSR can improve accessibility between the cities but disarticulates the space between these cities, thereby unlikely to increase inter-territorial cohesion and integration and may promote territorial polarization.

The strong interconnection between different means of public transport is essential for quality of the proposed HSR service by ensuring moderate competition with other means of transport. There is need to improve interconnection between big cities and accessibility of small and medium cities. Improvement in the interregional accessibility should be ensured to integrate intermediate cities along the HSR corridor to improve interconnection of markets. There is urgent need to improve accessibility to HSR station area to deal with expected traffic jams. It is necessary to improve station areas accessibility by developing public transport and car parks for greater effects of HSR project. The cooperation of all stakeholders, appropriate institutions, and coherence with the strategies of firms and labor market is needed. There is also need to evolve strategies for development of enterprises and tourisms, property markets and station area development.

\section{Limitations and Future Research}

In this ex-ante case study, the qualitative analysis has been based on the perceptions of the targeted population, because scant information was available, which compelled the researcher to depend on expectation, experience, and opinion of the targeted population. This is considered as a major limitation of the study, but not a barrier. The perceptions and expectations of the targeted population are the paramount, which the researcher has analyzed in initial stage of HSR development project. Nevertheless, this ex-ante case study has been a modest attempt to analyze the intended objectives with limited extant information and offered significant policy options. Additionally, the soundness of qualitative analysis can be a limitation as it becomes outdated faster. However, the authenticity of qualitative analysis can be stronger than strict quantitative analysis. The perceptions of the targeted population can persist longer and provide valuable initial insights for policy options and can supplement the quantitative analysis. Therefore, the future research can focus on comparing the results of the ex-ante impact analysis with ex-post quantitative impact study to ascertain the extent of achievement of the HSR development.

Conflicts of Interest: The author declares no conflict of interest.

Funding: This research received no external funding.

Informed Consent Statement: Informed consent was obtained from all subjects involved in the study.

Data Availability Statement: Data is contained within the article. 


\section{References}

1. Blanquart, C.; Koning, M. The local economic impacts of high-speed railways: Theories and facts. Eur. Transp. Res. Rev. 2017, 9, 1-14.

2. Coronado, J.M.; de Ureña, J.M.; Miralles, J.L. Short and long-term population and project implications of high-speed rail for served cities: Analysis of all served Spanish cities and re-evaluation of Ciudad Real and Puertollano, Eur. Plan. Stud. 2019, 27, 434-460.

3. Givoni, M.; Dobruszkes, F. A review of ex-post evidence for mode substitution and induced demand following the introduction of high-speed eail. Transp. Rev. 2013, 33, 720-742.

4. Dobruszkes, F.; Dehon, C.; Givoni, M. Does European high-speed rail affect the current level of air services? An EU-wide analysis. Transp. Res. Part A Policy Pract. 2014, 69, 461-475.

5. Campos, J.; De Rus, G. Some stylised facts about high-speed rail: A review of HSR experiences around the world. Transp. Policy 2009, 16, 19-28.

6. Wee, B.V.; Janse, P.; Brink, R.V.D. Comparing energy use and environmental performance of land transport modes. Transp. Rev. 2005, 25, 3-24.

7. Ahlfeldt, G.M.; Feddersen, A. From periphery to core: Measuring agglomeration effects using high-speed rail. J. Econ. Geogr. 2018, 18, 355-390.

8. Chen, Z.; Haynes, K.E. Impact of high-speed rail on regional disparity in China. J. Transp. Geogr. 2017, 65, 80-91.

9. Chen, C.-L.; Loukaitou-Sideris, A.; de Ureña, J.M.; Vickerman, R. Spatial short and long-term implications and planning challenges of high-speed rail: A literature review framework for the special issue, Eur. Plan. Stud. 2019, 27, 415-433.

10. Wang, S.; Wang, J.; Liu, X. How do urban spatial structures evolution in the high-speed rail era? Case study of Yangtze River Delta, China. Habitat Int. 2019, 93, 102051.

11. Yin, M.; Bertolini, L.; Duan, J. The effects of the high-speed railway on urban development: International experience and potential implications for China. Prog. Plann. 2015, 98, 1-52.

12. Chen, C.-L.; Hall, P. The wider spatial economic impacts of high speed trains: A comparative case study of Manchester and Lille sub-regions. J. Transp. Geogr. 2012, 24, 89-110.

13. Ahlfeldt, G.M.; Feddersen, A. From periphery to core: Measuring agglomeration effects using high-speed Rail. J. Econ. Geogr. 2017, 17, 1-16.

14. Guirao, B.; Lara-Galera, A.; Campa, J.L. High speed rail commuting impacts on labour migration: The case of the concentration of metropolis in the Madrid functional area. Land use policy 2017, 66, 131-140.

15. Vickerman, R. Can high-speed rail have a transformative effect on the economy? Transp. Policy 2018, 62, 31-37.

16. Chen, C.L.; Vickerman, R.W. Quantifying the Economic and Social Impacts of High-Speed Rail: Some Evidence from Europe and the People's Republic of China; Working Paper No.962; Asian Development Bank Institute: Tokyo, Japan, 2019; Available online: https://www.adb.org/publications/quantifying-economic-and-social-impacts-hsr-evidence-europe-prc (accessed on 13 July 2021).

17. Kanasugi, H.; Ushijima, K. The impact of a high-speed railway on residential land prices. Pap. Reg. Sci. 2017, 596, 1305-1335.

18. Wang, L. High-speed rail services development and regional accessibility restructuring in mega regions: A case of the Yangtze River delta, China. Transp. Policy 2018, 72, 34-44.

19. Chen, Z.; Xue, J.; Rose, A.Z.; Haynes, K.E. The impact of high-speed rail investment on economic and environmental change in China: A dynamic CGE analysis. Transp. Res. Part A Policy Pract. 2016, 92, 232-245.

20. Jayal, R. Of the People, for the People: Economic Corridors, High-Speed Railways, and Quality of Life in Post-COVID-19 Asia; ADBI Policy Brief No.2021-2; Asian Development Bank Institute: Tokyo, Japan, 2021; Available online: https://www.adb.org/publications/economic-corridors-high-speed-railways-quality-life-post-covid-19-asia (accessed on 15 May 2021).

21. Robertson, S. A carbon footprint analysis of renewable energy technology adoption in the modal substitution of high-speed rail for short-haul air travel in Australia. Int. J. Sustain. Transp. 2018, 12, $299-312$.

22. Moyano, A.; Martinez, H.S.; Coronado, J.M. From network to services: A comparative accessibility analysis of the Spanish high-speed rail system. Transp. Policy 2018, 63, 51-60.

23. Yoshino, N.; Abidhadjaev, U. Impact of infrastructure on tax revenue: Case study of high-speed train in Japan. J. Infrastruct. Policy Dev. 2017, 1, 1-20.

24. Zhang, G.; Zheng, D.; Wu, H.; Wang, J.; Li, S. Assessing the role of high-speed rail in shaping the spatial patterns of urban and rural development: A case of the Middle Reaches of the Yangtze River, China. Sci. Total Environ. 2020, 704, 135399.

25. Shibasaki R.; Miyazawa, S.; Seetha Ram, K.E.; Bharule, S. The Potential of Big Data for Boosting the Social Impact of Infrastructure Projects. In Handbook on High-Speed Rail and Quality of Life; Hayashi, Y., Seetha Ram, K.E., Bharule, S. Asian Development Bank Institute: Tokyo, Japan, 2020; pp. 139-146. Available online: https://www.adb.org/publications/handbook-high-speed-rail-quality-life (accessed on 15 April 2021).

26. Vickerman, R. Can high-speed rail have a transformative effect on the economy? Transp. Policy 2017, 62, 31-37. 
27. Lemoine, F.; Poncet, S.; Ünal, D. Spatial rebalancing and industrial convergence in China. China Econ. Rev. 2015, $34,39-63$.

28. Chai, J.; Zhou, Y.; Wang, S.; Zhang, Z.G.; Liu, Z. Analysis on shock effect of China's high-speed railway on aviation transport. Transp. Res. Part A Policy Pract. 2018, 108, 35-44.

29. Jiao, J.; Wang, J.; Jin, F. Impacts of high-speed rail lines on the city network in China. J. Transp. Geogr. 2017, 60, 257-266.

30. Yu, W.; Yao, Y. The route of development in intra-regional income equality via high speed rail: Evidence from China. In Proceedings of the 2019 Agricultural \& Applied Economics Association, Annual Meeting, Atlanta, GA, USA, 21-23 July 2019.

31. Beckerich, C.; Benoit, S.; Delaplace, M. Are the reasons for companies to locate around central versus peripheral high-speed rail stations different? The cases of Reims central station and Champagne-Ardenne station, Eur. Plan. Stud. 2019, 27, 574-594.

32. Matas, A.; Raymond, J.L.; Roig, J.L. Evaluating the impacts of HSR stations on the creation of firms, Transp. Policy 2020, 99, 396-404.

33. Zunder, T.; Islam, D. Assessment of existing and future rail freight services and technologies for low density high value goods in Europe. Eur. Transp. Res. Rev. 2018, 10, 9.

34. Diao, M.; Fan, Y.; Zhang, X. Introduction to special issue: Rail transit development in China and beyond. J. Transp. Land Use 2019, 12, 237-239.

35. Shen, Y.; Zhao, J.; De Abreu E Silva, J.; Martinez, L. From accessibility improvement to land development: A comparative study on the impacts of Madrid-Seville high-speed rail. Transp. Lett. 2017, 9, 1-15.

36. Ansar, A.; Flyvbjerg, B.; Budzier, A.; Lunn, D. Does infrastructure investment lead to economic growth or economic fragility? Evidence from China. Oxford Rev. Econ. Policy 2016, 32, 360-390.

37. Watson, I.; Ali, A.; Bayyati, A. Freight transport using high-speed railways. Int. J. Transp. Dev. Integr. 2019, 3, 103-116. .

38. Pagliara, F.; Mauriello, F. Modelling the impact of High Speed Rail on tourists with Geographically Weighted Poisson Regression. Transp. Res. Part A Policy Pract. 2020, 132, 780-790.

39. Wang, D.G.; Niu, Y.; Qian, J. Evolution and optimization of China's urban tourism spatial structure: A high speed rail perspective. Tour. Manag. 2018, 64, 218-232.

40. Gao, Y.; Su, W.; Wang, K. Does high-speed rail boost tourism growth? New evidence from China. Tour. Manag. 2019, 72, 220-231.

41. Wetwitoo J. How High-Speed Rail Fosters Japan's Regional Agglomeration Economy. In Handbook on High-Speed Rail and Quality of Life. In Handbook on High-Speed Rail and Quality of Life; Hayashi, Y., Seetha Ram, K.E., Bharule, S. Asian Development Bank Institute: Tokyo, Japan, 2020; pp. 96-111. Available online: https://www.adb.org/publications/handbook-high-speed-rail-quality-life (accessed on 15 April 2021).

42. ADBI. Financing Infrastructure in Asia and the Pacific: Capturing Impacts and New Sources. Asian Development Bank Institute: Tokyo, Japan, 2018. Available online: https://www.adb.org/publications/financing-infrastructure-asia-capturing-impacts-and-new-sources (accessed on 12 April 2021).

43. Seetha Ram, K.E.; Bharule, S.P. Spill-over and straw effects of HSR. Asian J. Transp. Infrastruct. 2019, 1, 114-122.

44. Wetwitoo, J.; Kato, H. High-speed rail and regional economic productivity through agglomeration and network externality: A case study of inter-regional transportation in Japan. Case Stud. Transp. Policy 2017, 5, 549-559.

45. Long, F.; Zheng, L.; Song, Z. High-speed rail and urban expansion: An empirical study using a time series of nighttime light satellite data in China. J. Transp. Geogr. 2018, 72, 106-118.

46. Jie, X., Ming, Z.; Xiaoling, Z.; Di, Z.; Yina, Z. How does city-cluster high-speed rail facilitate regional integration? Evidence from the Shanghai-Nanjing corridor. Cities 2019, 85, 83-97.

47. Zhihua, R.; Wenhua, L.; Sanggyun, N.; Xianhua, T.; Tianqiao, X. Regional marketization, OFDI, and sustainable employment: Empirical analysis in China. Sustainability 2019, 11, 4101-4118.

48. Zhao, Y.; Yu, H. A door-to-door travel time approach for evaluating modal competition of intercity travel: A focus on the proposed Dallas-Houston HSR route. J. Transp. Geogr. 2018, 72, 13-22.

49. Rothengatter W. Approaches to Measuring the Wider Economic Impacts of High-Speed Rail: Experiences from Europe. In Handbook on High-Speed Rail and Quality of Life; Hayashi, Y., Seetha Ram, K.E., Bharule, S. Asian Development Bank Institute: Tokyo, Japan, 2020; pp. 35-73. Available online: https:/www.adb.org/publications/handbook-high-speed-rail-quality-life (accessed on 15 April 2021).

50. Wang, J.; Du, D.; Huang, J. Inter-city connections in China: High-speed train vs. inter-city coach. J. Transp. Geogr. 2020, 82, 102619.

51. Cui, Q.; Wei, Y.-M.; Yu, C.-1.; Li, Y. Measuring the energy efficiency for airlines under the pressure of being included into the EU ETS. J. Adv. Transp. 2016, 50, 1630-1649.

52. Wee, B.V. Accessible accessibility research challenges. J. Transp. Geogr. 2016, 51, 9-16.

53. Xinze, L.; Xiaole, L.; Lingling, Z. Can high-speed rail improve enterprise resource allocation? Microscopic evidence from Chinese industrial enterprise database and high-speed rail geographic data. Econ. Rev. 2017, 6, 3-21.

54. Boulton, C.; Dedekorkut-Howes, A.; Byrne, J. Factors shaping urban greenspace provision: A systematic review of the literature. Landsc. Urban Plan. 2018, 178, 82-101. 
55. Jiao, J.; Wang, J.; Zhang, F.; Jin, F.; Liu, W. Roles of accessibility, connectivity and spatial interdependence in realizing the economic impact of high-speed rail: Evidence from China. Transp. Policy 2020, 91, 1-15.

56. Nakamura, H.; Nagasawa, K.; Hiraishi, K.; Hasegawa, A.; Seetha Ram, K.E.; Kim, C.J.; Xu, K. Principles of Infrastructure: Case Studies and Best Practices. Asian Development Bank Institute and Mitsubishi Research Institute, Inc.: Tokyo, Japan, 2019. Available online: https://www.adb.org/publications/principles-infrastructure-case-studies-best-practices (accessed on 14 March 2021)

57. Renzhi N. How High-Speed Rail Affects Local Land Prices: Evidence from Taipei, China. In Handbook on High-Speed Rail and Quality of Life; Hayashi, Y., Seetha Ram, K.E., Bharule, S. Asian Development Bank Institute: Tokyo, Japan, 2020 ; pp. 74-95. Available online: https://www.adb.org/publications/handbook-high-speed-rail-quality-life (accessed on 15 April 2021).

58. Yoshino N.; Xu, K.; Seetha Ram, K.E. Land Trust Scheme and the Spillover Effects of Infrastructure Investment. In Handbook on High-Speed Rail and Quality of Life; Hayashi, Y., Seetha Ram, K.E., Bharule, S. Asian Development Bank Institute: Tokyo, Japan, 2020; pp. 18-34. Available online: https://www.adb.org/publications/handbook-high-speed-rail-quality-life (accessed on 15 April 2021).

59. Pagliara, F.; Mauriello, F.; Garofalo, A. Exploring the interdependences between high speed rail systems and tourism: Some evidence from Italy. Transp. Res. Part A Policy Pract. 2017, 106, 300-308.

60. Zhou, B.; Li, N. The impact of high-speed trains on regional tourism economies: Empirical evidence from China. Tour. Econ. 2017, 24, 187-203.

61. Facchinetti-Mannone, V. A methodological approach to analyze the territorial appropriation of high-speed rail from interactions between actions and representations of local actors. Eur. Plan. Stud. 2019, 27, 461-482.

62. Beckerich, C.; Benoit-Bazin, S.; Delaplace, M. Does high speed rail affect the behaviour of firms located in districts around central stations? The results of two surveys conducted in Reims in 2008 and 2014. Transp. Res. Procedia 2017, 25, 3017-3034.

63. Crescenzi, R.; Di Cataldo, M.; Andrés Rodríguez-Pose, A. Government quality and the economic returns of transport infrastructure investment in European Regions. J. Reg. Sci. 2016, 56, 555-582.

64. Atkinson, P.; Coffey, A.; Delamont, S. A debate about our canon. Qual. Res. 2001, 1, 5-21.

65. Punch, K.F. Introduction to Social Research: Quantitative and Qualitative Approaches. SAGE Publications: Los Angeles, US, 2013.

66. Pistol, L.; Bucea-Manea-Tonis, R. Model of simulation for optimizing marketing mix through conjoint analysis case study: Launching a product on a new market. Econ. World. 2017, 5, 311-315.

67. Bourguignon, F.; Ferreira, F.H.G. Ex Ante Evaluation of Policy Reforms using Behavioral Models. In The Impact of Economic Policies on Poverty and Income Distribution: Evaluation, Techniques and Tools; Bourguignon, F., Pereira da Silva, L., Eds., World Bank and Oxford University Press: Washington DC, US, 2003; pp. 123-141.

68. Creswell, J.W. Research Design: Qualitative, Quantitative and Mixed Method Approaches (3rd Ed.). SAGE Publications: Los Angeles, US, 2009.

69. Simons, H. Case Study Research in Practice. SAGE: London, UK, 2009.

70. Chen, Z. H.; Haynes, K.E. Impact of high-speed rail on international tourism demand in China. Appl. Econ. Lett. 2015, 22, 57-60.

71. IBEF. Railways; India Brand Equity Foundation: New Delhi, India, 2019.

72. García Mejuto, D. A Europe of multiple flows: Contested discursive integration in trans-European transport infrastructure policy-making. Eur. Urban Reg. Stud. 2017, 24, 425-441. 